\title{
Automatic classification of manual snow profiles by snow structure
}

\author{
F. Techel and C. Pielmeier \\ WSL Institute for Snow and Avalanche Research SLF, 7260 Davos, Switzerland \\ Correspondence to: F. Techel (techel@slf.ch)
}

Received: 22 November 2013 - Published in Nat. Hazards Earth Syst. Sci. Discuss.: 12 December 2013

Revised: - Accepted: 25 February 2014 - Published: 10 April 2014

\begin{abstract}
Manual snowpack observations are an important component of avalanche hazard assessment for the Swiss avalanche forecasting service. Approximately 900 snow profiles are observed each winter, in flat study plots or on representative slopes. So far, these profiles have been manually classified combining both information on snow stability (e.g. Rutschblock test) and snowpack structure (e.g. layering, hardness). To separate the classification of snowpack stability and structure, and also to reduce inconsistencies in ratings between forecasters, we developed and tested an automatic approach to classify profiles by snowpack structure during two winters. The automatic classification is based on a calculated index, which consists of three components: properties of (1) the slab (thickness), (2) weakest layer interface and (3) the percentage of the snowpack which is soft, coarsegrained and consists of persistent grain types. The latter two indices are strongly based on criteria described in the threshold sum approach. The new snowpack structure index allows a consistent comparison of snowpack structure to detect regional patterns, seasonal or inter-annual differences but may also supplement snow-climate classifications.
\end{abstract}

\section{Introduction}

Snowpack information is, among other data, one important source for assessing the avalanche danger. Snowpack observations ideally incorporate observations on snow stratigraphy, failure initiation and crack propagation (McCammon and Sharaf, 2005). Characteristics of the snowpack layering are crucial to the failure initiation (strength, e.g. observed with the Rutschblock score; Föhn, 1987) and the crack propagation process (toughness, e.g. observed with the Rutschblock release type; Schweizer et al., 2008). Properties of weak layer or layer interfaces and the slab overlying a weak layer play a role in the fracture process necessary for dry-snow slab avalanches (e.g. van Herwijnen and Jamieson, 2007; Sigrist and Schweizer, 2007).

\subsection{Unfavourable snowpack structure}

Several studies compared stable and unstable snowpack conditions - generally profiles in slopes which were not triggered by skiers vs. those which were triggered or where signs of instability like whumpfs, shooting cracks and recent avalanching were observed (e.g. Simenhois and Birkeland, 2006; Winkler and Schweizer, 2009). The focus in these studies was generally on snow stability (stability tests). However, snow structure was also investigated. One important result was the threshold sum approach (TSA, e.g. Schweizer and Jamieson, 2007), which describes typical ranges of snowpack parameters associated with snow instability (Table 1).

Slab properties also play a fundamental role in crack propagation leading to avalanche release (van Herwijnen and Jamieson, 2007). The slab is generally defined as the layer which slides in an avalanche or a stability test above a weak layer. Slab properties related to skier-triggering of dry-snow slab avalanches include layering within the slab, grain type, thickness, density and hardness, as well as the differences between slab and weak layer (e.g. Schweizer and Lütschg, 2001; van Herwijnen and Jamieson, 2007; Habermann et al., 2008).

Many skier-triggered and fatal avalanches release in socalled persistent weak layers (e.g. Schweizer and Lütschg, 2001). The distinction between persistent and non-persistent weak layers is based on the following: 
Table 1. Relevant snowpack criteria described in the threshold sum approach - TSA (Schweizer and Jamieson, 2007).

\begin{tabular}{lll}
\hline & Variable & Critical range \\
\hline \multirow{2}{*}{ Layer } & hardness (index) & $\leq 1.3$ \\
& grain size $(\mathrm{mm})$ & $\geq 1.25$ \\
& grain type & persistent \\
Layer interface difference & grain size $(\mathrm{mm})$ & $\leq 0.75$ \\
& difference in hardness (index) & $\geq 1.7$ \\
& slab thickness or failure layer depth $(\mathrm{cm})$ & $18 \ldots 94$ \\
\hline
\end{tabular}

- grain type - persistent grain types are those considered following temperature-gradient metamorphism as facets and depth hoar (Jamieson and Johnston, 1998) and also surface hoar,

- a combination of snowpack and avalanche observations, where a persistent weakness is one which was still active 10 days after its formation (resulting in avalanche activity on this layer) (Haegeli and McClung, 2007)

\subsection{Snowpack observations and classification scheme currently used in Switzerland}

In Switzerland, snowpack structure and stability is regularly investigated in the extensive observation programme of the Swiss avalanche warning centre in all regions in the Swiss Alps. Manual snow profiles are observed by SLF (WSL Institute for Snow and Avalanche Research SLF) observers twice a month on level study plots (mostly below tree line) and on representative slopes (mostly above tree line). This information provides an invaluable source for the avalanche forecasters to assess snowpack structure (e.g. presence and regional distribution of weak layers) and snow stability (slope profiles only).

These profiles are manually classified according to the stability classification scheme introduced by Schweizer and Wiesinger (2001), called hereafter stab ${ }_{01}$. The stab ${ }_{01}$ classification approach combines information on snow stability (e.g. Rutschblock score) and snowpack structure. Some of the key parameters defining the stability class assigned to a profile are the Rutschblock score and release type (e.g. Föhn, 1987; Schweizer, 2002), presence of weak layers and layer interfaces, presence and hardness of slab or weak layers and the profile type. Profiles are classified from 1 (very poor) to 5 (very good). A more detailed overview is given in Schweizer and Wiesinger (2001). The stab ${ }_{01}$-classification scheme is primarily a stability classification: Rutschblock information generally has a higher weight and overrules profile type or weak layer information (Schweizer and Wiesinger, 2001).

Profiles not containing a stability test, as those in flat study plots, are therefore not classified. The classification scheme allows considerable room for a subjective interpretation of snow stability.
From the warning service perspective, it was felt necessary

- to differentiate between snowpack structure and snow stability information:

- snow stability is relevant in the short term and is described twice daily in the avalanche bulletin; snowpack weaknesses may be found within the new snow or storm snow as well as in persistent weak layers deep in the snowpack.

- snowpack structure is of interest particularly in the long term (base for new snow, structure before wetting); here the focus is on persistent weaknesses.

- to have a systematic, consistent and objective index of snowpack structure relevant to avalanche forecasting facilitating the spatial and temporal analysis of snowpack observations and reducing discrepancies between different forecasters' subjective snow profile rating.

- to increase the number of profiles available for analysis by including profiles without stability information

- to reduce the workload necessary for manual classification of snow profiles.

In this paper we describe a method to automatically classify snowpack structure for manual snow profiles based on slab and weak layer properties.

\section{Data and methods}

Snow profile observations in Switzerland follow the international recording standard for snow profile observations (Fierz et al., 2009). Observation procedures are highly standardized, and observers are trained by the avalanche warning service. The investigated snow layering information consists of snow depth, thickness, hardness, grain shape, grain size and wetness of each layer. Snow temperatures are measured in $10 \mathrm{~cm}$ increments. Often, a ram profile accompanies the snow profiles (90\% of profiles). Snow water equivalent is measured in flat study plots (50\% of profiles), while on potential avalanche slopes a stability test, generally the Rutschblock 
Table 2. Selection of some of the most important, investigated snowpack parameters.

\begin{tabular}{|c|c|c|c|}
\hline & Variable & & Definition \\
\hline \multirow[t]{16}{*}{ Full profile } & snow depth & hs & {$[\mathrm{cm}]$} \\
\hline & grain type & $\mathrm{FC}_{\text {prop }}$ & $\begin{array}{l}\text { proportion of snowpack which is either classified as per- } \\
\text { sistent (FC, DH, SH), }\end{array}$ \\
\hline & & $\mathrm{NP}_{\text {prop }}$ & non-persistent (PP, DF, RG) or \\
\hline & & MF prop & melt form (MF, IF) \\
\hline & grain size & size $^{T^{2}}$ & mean $[\mathrm{mm}]$ \\
\hline & hand hardness & hardness & mean [index] \\
\hline & ram hardness & ram & mean $[\mathrm{N}]$ \\
\hline & temperature & ts & mean $\left[{ }^{\circ} \mathrm{C}\right]$ \\
\hline & wetness & wetness & mean $[$ index $]$ \\
\hline & profile type (ram profile) & & $\begin{array}{l}\text { Categorical classification, } 10 \text { types (Schweizer and } \\
\text { Wiesinger, 2001) }\end{array}$ \\
\hline & Rutschblock stability & $\mathrm{RB}_{\text {stab }}$ & $\begin{array}{l}\text { Ordinal classification by RB score and RB release type } \\
\text { (Table 3) }\end{array}$ \\
\hline & stability classification & $\operatorname{stab}_{01}$ & $\begin{array}{l}\text { Ordinal classification according to Schweizer and } \\
\text { Wiesinger (2001) }\end{array}$ \\
\hline & proportion coarse grained, soft layers & size $_{\text {prop }}$ & $\begin{array}{l}\text { proportion of snowpack which is coarse-grained (grain } \\
\text { size } \geq 1.25 \text { ) AND has a hand hardness } \leq 3 \text {, relative to } \\
\text { hs }\end{array}$ \\
\hline & proportion persistent, soft layers & $\mathrm{PG}_{\text {prop }}$ & $\begin{array}{l}\text { proportion of snowpack which consists of persistent } \\
\text { grain type AND has a hand hardness } \leq 3 \text {, relative to hs }\end{array}$ \\
\hline & proportion very soft layers & hard $_{\text {prop }}$ & $\begin{array}{l}\text { proportion of snowpack which is very soft (hand hard- } \\
\text { ness } \leq 1.3 \text { ), relative to hs }\end{array}$ \\
\hline & layer threshold sum & TSA $_{\text {layer }}$ & size $_{\text {prop }}+\mathrm{PG}_{\text {prop }}+$ hard $_{\text {prop }}$ \\
\hline \multirow[t]{3}{*}{ Weak layer } & persistent weak layer & $p_{\mathrm{wL}}$ & $\begin{array}{l}1 / 0-1 \text { if the three TSA layer criteria (grain type, grain } \\
\text { size, hardness) are fulfilled in same layer (Table } 1 \text { ); else } \\
0\end{array}$ \\
\hline & non-persistent weak layer & $n p_{\mathrm{wL}}$ & $\begin{array}{l}1 / 0-1 \text { if criteria grain type (PP, DF) AND hardness } \\
\leq 1.5 \text { AND size } \geq 1 \mathrm{~mm} \text { are fulfilled in same layer; else } \\
0\end{array}$ \\
\hline & weak layer proportion & $w L_{\text {prop }}$ & $\begin{array}{l}\text { proportion of thickness of layers where } p_{\mathrm{wL}}=1 \text {, rela- } \\
\text { tive to hs }\end{array}$ \\
\hline Layer interface & layer interface threshold sum & $\mathrm{TSA}_{\max }$ & $\begin{array}{l}\text { threshold sum for layer interface with maximum score } \\
\text { (Table 1) }\end{array}$ \\
\hline \multirow[t]{5}{*}{ Slab } & thickness & slab $_{\text {thick }}$ & $\begin{array}{l}\text { all layers above the persistent weak layer closest to the } \\
\text { snow surface (where } p_{\mathrm{wL}}=1 \text { ), but at least } 15 \mathrm{~cm} \text { be- } \\
\text { low the snow surface, if no persistent weak layer, then } \\
\text { slab }_{\text {thick }}=\text { hs }\end{array}$ \\
\hline & hardness & slab hard & $\begin{array}{l}\text { weighted mean of the hand hardness of the slab } \\
\sum_{p_{\mathrm{wL}}=1}^{\text {snow_surface }}\left(h_{i} \cdot H_{i}\right)\end{array}$ \\
\hline & strength & slab strength & $\begin{array}{l}H_{i} \text { the hand hardness of each layer within the slab } \\
\text { a slab strength index, as in Winkler and Schweizer } \\
(2009): \sum_{p_{\mathrm{wL}}=1}^{\text {snow_surface }}\left(h_{i} \cdot H_{i}^{2}\right) \text {, where } h_{i} \text { is the thick- } \\
\text { ness and } H_{i} \text { the hand hardness of each layer within the } \\
\text { slab }\end{array}$ \\
\hline & bridging & slab bridging & $\begin{array}{l}\text { slab }_{\text {hard }} \times \text { slab }_{\text {thick }} \text { as in Schweizer and Jamieson (2003) } \\
\sum_{p_{\mathrm{w}}=1}^{\text {snow_surface }}\left(h_{i} \cdot \frac{\text { size }_{i}}{H .}\right)\end{array}$ \\
\hline & texture & slab texture & $\begin{array}{l}\text { slab } p_{\mathrm{wL}}=1 \\
\text { size }_{i} \text { the grain size and } H_{i} \text { the hand hardness of each } \\
\text { layer within the slab }\end{array}$ \\
\hline
\end{tabular}


Table 3. Classification of profile stability based on the Rutschblock (RB) test result in five classes $\left(\mathrm{RB}_{\text {stab }}\right)$ based on $\mathrm{RB}$ score (score 1-7) and RB release type. The classification is based on the stability classification scheme by Schweizer and Wiesinger (2001)). RB release type: $w B 1$ - whole block, $\mathrm{pBr}$ - partial break, Edg - edge only.

\begin{tabular}{llll}
\hline RB $_{\text {stab }}$ & Score, release type & & \\
\hline 1 & RB1 all & RB2 wB1 & \\
2 & RB2 $\mathrm{pBr}$ OR Edg & RB3 wB1 & \\
3 & RB3 $\mathrm{pBr}$ OR Edg & RB4 all & RB5 wB1 \\
4 & RB5 $\mathrm{pBr}$ OR Edg & RB6 wB1 & \\
5 & RB6 pBr OR Edg & RB7 & \\
\hline
\end{tabular}

test (Föhn, 1987), complements the snow profile observations (50\% of profiles). Layer-specific snow density is hardly measured.

To develop an objective classification of snow structure, we randomly selected 258 profiles from the SLF snowprofile database (profiles with poor recording quality were rejected) and asked 9 experienced (current and previous) SLF avalanche forecasters to rate the snowpack structure based solely on layering information by excluding information on location and snow stability and removing any additional text information describing snow and avalanche conditions. Snowpack structure was classified from 1 (unfavourable) to 5 (favourable). Each profile was assessed by at least two and up to four forecasters. For further analysis, we used the mean snowpack structure rating for each profile (hereafter called $\mathrm{SNPK}_{\text {manual }}$ ).

Snowpack parameters related to unstable snow conditions and dry-snow slab avalanche release were calculated from the layering information (Table 2). Calculated parameters included simple means or sums over the full profile, but of particular interest were properties providing weak layer and slab information. A slab layer is defined as a layer of bonded snow above a weak layer. Current snow profile observation procedures do not distinguish between very soft layers (hand hardness index 1) of bonded snow and very soft layers of cohesionless snow (hand hardness 1). As the $\mathrm{SNPK}_{\text {manual was }}$ based on layering information only - no stability test identified the slab and the relevant weak layer - the slab was defined as all layers above the persistent weak layer closest to the surface but with a minimum depth of $15 \mathrm{~cm}$. A value of $15 \mathrm{~cm}$ was chosen as a minimum threshold for a relevant slab depth and corresponds closely to the TSA approach (Table 1). Grain shape was classified as persistent and non-persistent (Jamieson and Johnston, 1998) or melt form.

In a first step, we compared the existing classification $\left(\operatorname{stab}_{01}\right)$ with the manually classified snow structure $\left(\mathrm{SNPK}_{\text {manual }}\right)$ and stability information (Rutschblock test). For the latter, the Rutschblock result was classified in five classes by Rutschblock score and release type $\left(\mathrm{RB}_{\mathrm{stab}}, \mathrm{Ta}-\right.$ ble 3).
To investigate the relevance of the snowpack parameters for the manual snow structure assessment, we used the nonparametric Spearman rank order correlation testing for a monotonic relationship (Crawley, 2007) and conditional inference trees (ctree, R package party; Hothorn et al., 2006) to investigate which properties are most relevant for snowpack structure classification. Results were considered significant if the level of significance $\alpha \leq 0.05$.

Based on the outcome of the uni-variate and multi-variate analysis, we developed a snow structure index incorporating some of the most relevant variables describing slab, weak layer and layer interfaces.

\section{Results and discussion}

As both the Rutschblock test and snowpack criteria are important components of the existing stab $_{01}$ classification, it is not surprising that they are both correlated to $\operatorname{stab}_{01}\left(\mathrm{RB}_{\text {stab }}\right.$ : $\left.\rho=0.65, \mathrm{SNPK}_{\text {manual }}: \rho=0.50\right)$. The correlation between stability information $\left(\mathrm{RB}_{\mathrm{stab}}\right)$ and manual snow structure classification $\left(\mathrm{SNPK}_{\text {manual }}\right)$, however, is significant but much weaker $(\rho=0.33)$. This highlights that snowpack structure and snowpack stability do not necessarily develop in the same direction. For instance, a prolonged cold dry period might lead to an increase in snow stability, while at the same time temperature-gradient metamorphism results in a more unfavourable snowpack structure for future snowfall or snow loading by wind events.

The profile type classification (based on the ram hardness profile; Schweizer and Wiesinger, 2001) showed few associations to $\mathrm{SNPK}_{\text {manual }}$. The two exceptions were a profile which was very soft throughout was rated mostly as unfavourable, and a profile which was very hard throughout was rated mostly favourable. While the ram hardness method is a more objective measurement technique than the hand hardness method, small thin layers and differences in soft layers are not detected using this method. Also, the ram probe is used for hardness measurements almost exclusively in Switzerland. Therefore this approach was not further investigated.

\subsection{Snowpack variables related to manual snowpack structure classification}

\subsubsection{Univariate analysis}

The calculated snowpack parameters were tested for their relevance to $\mathrm{SNPK}_{\text {manual }}$ (Table 4).

Slab properties $\left(\mathrm{slab}_{\text {strength }}, \mathrm{slab}_{\text {bridging }}, \mathrm{slab}_{\text {thick }}\right)$ showed moderate to strong correlation $(\rho=[0.69,0.72])$. Layer interface information $\left(\mathrm{TSA}_{\max }\right)$ and weak layer information ( $\mathrm{wL}_{\text {prop}}, \mathrm{TSA}_{\text {layer }}$ ) showed moderate correlation to $\mathrm{SNPK}_{\text {manual }}$ 
Table 4. Relevance/contribution of snow stability and snowpack structure observations for stability assessment according to Schweizer and Wiesinger (2001, $\mathrm{stab}_{01}$, right part of table). Parameters were subjectively ranked by nine experienced forecasters (score between 0 - not important and 1 - very important). The left part of the table shows the approximately corresponding parameters for the presented study. For these variables, the Spearman correlation $\rho$ to the manually classified snowpack structure $\left(\mathrm{SNPK}_{\text {manual }}\right)$ is given. The correlation is not for all investigated parameters shown. * Profile type (nominal variable) - no correlation calculated.

\begin{tabular}{lllll}
\hline $\begin{array}{l}\text { Snowpack variable } \\
\text { current study }\end{array}$ & $\rho$ & $\begin{array}{l}\text { Sign of } \\
\text { correlation }\end{array}$ & $\begin{array}{l}\text { Snowpack variable } \\
\text { (Schweizer and Wiesinger, 2001) }\end{array}$ & $\begin{array}{l}\text { Subjective } \\
\text { relevance }\end{array}$ \\
\hline $\begin{array}{l}\text { wL } L_{\text {prop }} \\
\text { profile type }\end{array}$ & 0.59 & - & weak layers & 1 \\
$\mathrm{RB}_{\text {stab }}$ & $*$ & & profile type & 1 \\
slab & 0.33 & + & Rutschblock & 0.9 \\
size & 0.69 & + & slab thickness & 0.9 \\
FC & 0.43 & - & grain size & 0.7 \\
hs & 0.39 & - & grain type & 0.7 \\
ts & 0.47 & + & snow depth & 0.6 \\
hardness & 0.01 & + & snow temperature & 0.5 \\
slab & 0.59 & + & hand hardness & 0.4 \\
wetness $_{\text {TSA }}$ & 0.72 & + & slab hardness & 0.4 \\
TSA $_{\text {layer }}$ & 0.02 & + & liquid water content & 0.1 \\
stab $_{01}$ & 0.60 & - & & \\
\hline
\end{tabular}

Many of the snowpack variables describing slab properties, weak layers or weak layer interfaces are moderately or strongly correlated to $\mathrm{SNPK}_{\text {manual }}$. However, they all have some shortcomings: for instance, slab properties are particularly suitable for discrimination of intermediate to favourable snowpack structure, while parameters related to weak layers and weak layer interfaces are most useful to distinguish between intermediate and unfavourable snowpack classes. Therefore, a combination of different parameters seems most plausible and is also consistent with previous research.

\subsubsection{Classification tree approach}

Additionally to the correlation analysis, we used classification tree analysis to investigate which properties are most relevant to classify snowpack structure. A combination of slab properties $\left(\mathrm{slab}_{\text {strength }}\right.$, slab bridging $_{\text {, }}$, slab thick $\left._{\text {the }}\right)$ and weak layer criteria $\left(\mathrm{TSA}_{\text {layer }}, p_{\mathrm{wL}}\right)$, as well as the overall mean grain size, was most suitable for the classification of the snowpack structure. The classification accuracy of this classification tree was $64 \%$ of profiles classified correctly, $31 \% \pm 1$ class and $4 \% \pm 2$ classes.

\subsubsection{Snowpack structure index}

Further, we developed a continuous index variable for snowpack structure.

One of the requirements for this index was that it incorporates information relevant to dry-snow slab avalanche initiation and propagation. Thus, we forced the index to contain at least one parameter describing the slab, weak layer interfaces and layer properties. Selection criteria to obtain the most suitable three parameters were

1. preferably a strong correlation to the manual snowpack structure classification and

2. preferably no correlation between the selected variables.

As all variables contributing to snowpack structure were significantly correlated to each other, we selected those with the lowest correlation between each other. For instance, the slab variables slab $\mathrm{b}_{\text {strength }}$ and slab bridging showed a marginally better correlation to $\mathrm{SNPK}_{\text {manual }}$ than slab $\mathrm{b}_{\text {thick }}$ and were also selected by the classification tree analysis, but they showed a much stronger correlation to weak layer interfaces (TSA $\mathrm{max}_{\text {ax }}$ ) and layer properties $\left(\mathrm{TSA}_{\text {layer }}\right)$ than slab $\mathrm{b}_{\text {thick }}$.

Also, for the presented index, hereafter called $\mathrm{SNPK}_{\text {index }}$, we selected relatively basic criteria, which are easy to calculate (e.g. slab thickness) and/or are based on existing snowpack assessment procedures (in particular the threshold sum approach TSA, Table 1). Box plots for the three selected parameters $\mathrm{TSA}_{\text {layer }}, \mathrm{TSA}_{\max }$ and slab thick are shown in Fig. 1.

To combine several parameters with different units or ranges of values, the parameters had to be standardized. About one dozen combinations of three different parameters were tested. Most of these combinations performed with similar quality and only marginally better than using only one or two parameters. However, using three parameters reduced the bias in the classification error with a similar number of profiles classified better or worse than the manual classification. 

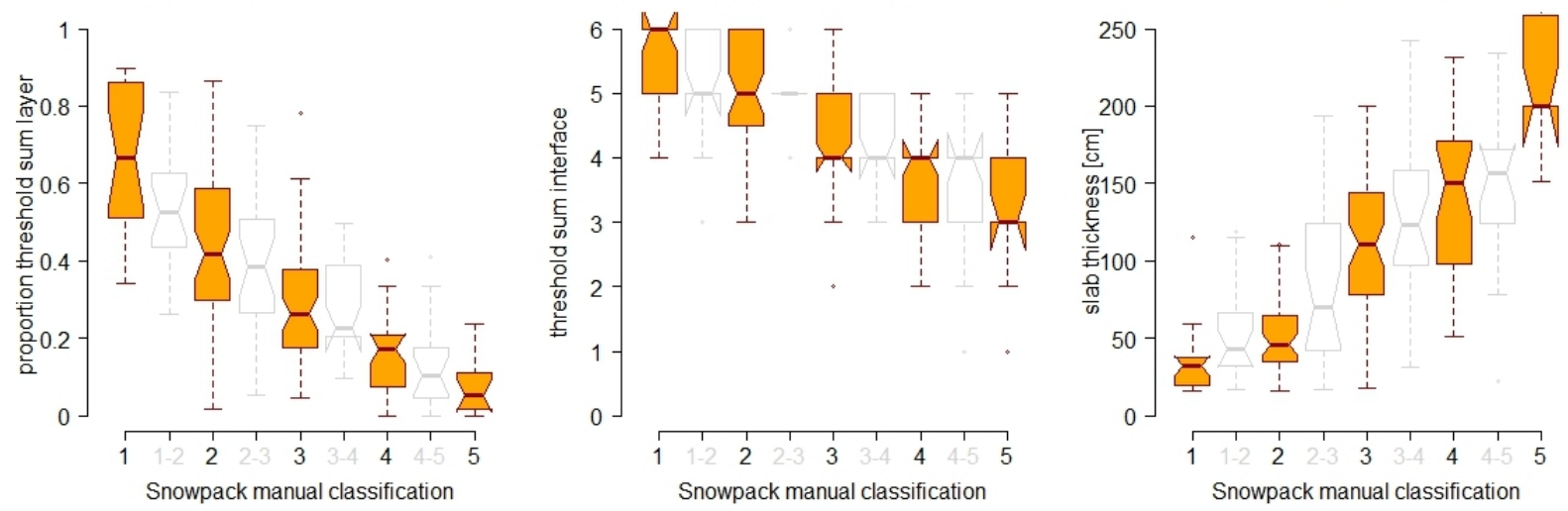

Fig. 1. Box plots showing variables selected for the snowpack index $\left(\mathrm{SNPK}_{\text {index }}\right)$ and their distribution relative to the manually classified snowpack structure $\left(\mathrm{SNPK}_{\text {manual }}\right)$ : threshold sum approach for layers (left) and layer interfaces (centre) and depth of persistent weak layer (right). All three variables are strongly correlated to $\mathrm{SNPK}_{\text {manual }}$ and moderately correlated to each other.

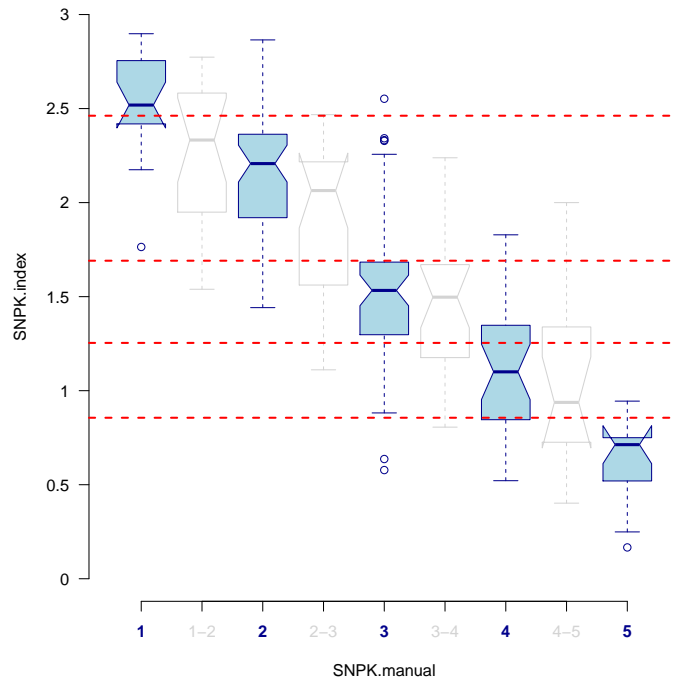

Fig. 2. Box plots showing the $\mathrm{SNPK}_{\text {index }}$ and the manually classified snowpack structure $\left(\mathrm{SNPK}_{\text {manual }}, 1\right.$ - unfavourable to 5 favourable). The red lines represent the $\mathrm{SNPK}_{\text {index }}$ splitting thresholds between full $\mathrm{SNPK}_{\text {manual }}$ classes (light-blue boxes), as obtained with the classification tree analysis (Table 5). The correlation between the index and the manual classification (including profiles which were classified with half classes, light boxes) is strong $\left(\rho=0.79, p<10^{-16}\right)$.

The calculation of the $\mathrm{SNPK}_{\text {index }}$ consists of three separate calculations, each standardizing one parameter to values between 0 (favourable) and 1 (unfavourable):

1. The first part of the index describes the proportion of the snowpack which is very soft hard prop $_{\text {and the pro- }}$ portion which is coarse-grained size prop $_{\text {and the pro- }}$ portion which consists of persistent grain type $\mathrm{PG}_{\text {prop }}$ (see Tables 1 and 2), standardized by the number of the three components.

$$
\begin{aligned}
& \mathrm{TSA}_{\text {layer }_{\text {index }}}= \\
& \quad \frac{\mathrm{TSA}_{\text {layer }}}{3}=\frac{\text { hard }_{\text {prop }}+\text { size }_{\text {prop }}+\mathrm{PG}_{\text {prop }}}{3} .
\end{aligned}
$$

2. The second part of the index uses the maximum score of the threshold sum approach for layer interfaces, standardized by the maximum possible score.

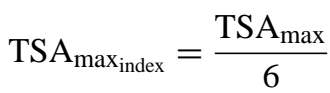

3. The third part of the index incorporates a slab parameter, the standardized slab thickness.

$\operatorname{slab}_{\text {depth }_{\text {index }}}=\left|\frac{\text { slab }_{\text {thick }}-30}{170}-1\right|$.

The slab thickness is standardized to values between 1 (thickness $30 \mathrm{~cm}$, which corresponds roughly to the median of slab thickness $(32.5 \mathrm{~cm})$ for $\mathrm{SNPK}_{\text {manual }}$ class 1 and is similar to slab thickness values described in van Herwijnen and Jamieson (2007)) and 0 (thickness $200 \mathrm{~cm}$ which corresponds to median of slab thickness for $\mathrm{SNPK}_{\text {manual }}$ class 5, see also Fig. 2,

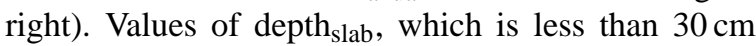
(or greater than $200 \mathrm{~cm}$ ), are accordingly assigned a $\mathrm{slab}_{\text {depth }_{\text {index }}}$ of 1 (or 0 ).

The SNPK $_{\text {index }}$ is then calculated as

$\mathrm{SNPK}_{\text {index }}=\mathrm{TSA}_{\text {layer }_{\text {index }}}+\mathrm{TSA}_{\text {max }_{\text {index }}}+\mathrm{slab}_{\mathrm{depth}_{\text {index }}}$.

The continuous $\mathrm{SNPK}_{\text {index }}$ has a range from 0 (very favourable) to 3 (very unfavourable).

The SNPK $_{\text {index }}$ is strongly correlated to the manual snow structure classification $\mathrm{SNPK}_{\text {manual }}\left(\rho=0.79, p<10^{-16}\right.$, Fig. 2). 


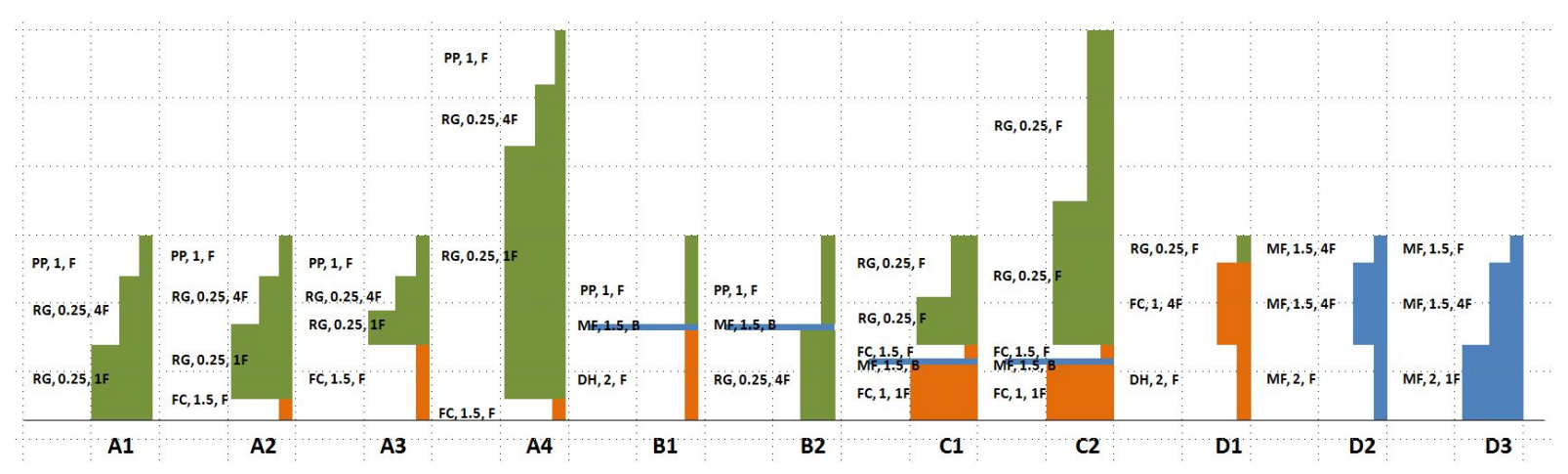

Fig. 3. Simplified snow profiles. The hand hardness profile is shown with the main grain type (colour) indicated. Layer properties (text) are given for each layer in the following order: grain type, grain size ( $\mathrm{mm})$, and hand hardness. Abbreviations are according to Fierz et al. (2009).

Applying the classification tree method to the SNPK index results in significant splitting thresholds for all five $\mathrm{SNPK}_{\text {manual }}$ classes (Table 5). Using these thresholds to classify the 258 profiles results in $64 \%$ of profiles being classified correctly, $32 \% \pm 1$ class and $4 \% \pm 2$ classes.

\subsection{Examples}

The application of the $\mathrm{SNPK}_{\text {index }}$ to a typical selection of (simplified) profiles (Fig. 3) is shown in Table 6.

The simplified profiles show the following:

- Profile A1 has no persistent weaknesses, while profiles A2 to A4 have similar slab layering but with a persistent weak layer and slab combination.

- Profiles B1 and B2 are two rather soft profiles, both with a melt-freeze crust in the middle of the profile. While $\mathrm{B} 1$ has a faceted base (DH), the base of $\mathrm{B} 2$ is composed of small round grains.

- C1 and C2 contain a prominent persistent weakness below a slab of varying thickness.

- Profiles D1 (dry) to D2 and D3 (wet) are examples of typical spring snowpack-type evolution.

The $\mathrm{SNPK}_{\text {index }}$ was calculated with a snow depth of $2 \mathrm{~m}$ for profiles A4 and $\mathrm{C} 2$, otherwise with $1 \mathrm{~m}$. To compare the index (Table 6, row 1) and the automatically calculated classes from the index (row 2) with the manual classification, four forecasters classified these simplified profiles as before (Table 6, row 3). Again, the classification accuracy was similar to before: $64 \%$ of profiles being classified correctly or within $\pm \frac{1}{2}$ class, $27 \% \pm 1$ class and $9 \% \pm 2$ classes.

\section{Conclusions}

We have developed an automatic snowpack classification algorithm, which considers slab, weak layer and weak layer interface properties as observed in manual snow profiles.
Table 5. Best-splitting $\mathrm{SNPK}_{\mathrm{index}}$ thresholds to classify profiles in five classes.

\begin{tabular}{ll}
\hline Threshold between classes & SNPK $_{\text {index }}$ threshold \\
\hline 1 and 2 & 2.462 \\
2 and 3 & 1.687 \\
3 and 4 & 1.254 \\
4 and 5 & 0.788 \\
\hline
\end{tabular}

The index has a focus on persistent weak layers, which are frequently the failure layer associated with snow instability (Schweizer and Jamieson, 2007). Due to the lack of information on the bonding of very soft surface layers, the minimal potential slab depth was defined solely by the depth of the uppermost persistent weak layer.

The main advantage of the index is the automatic, objective classification of snowpack structure in regard to drysnow slab avalanche release. Like any statistical approach, the index has its limitations: about two thirds of the profiles were classified in the same class as the manual snowpack structure assessment. However, only very few profiles were misclassified by two classes. Also, the index has no bias towards a better or worse classification. While the index is an objective approach to classify snowpack structure, it must be kept in mind that it relies on highly standardized but subjective observations (particularly hand hardness, grain type and size are to some extent observer dependent).

Currently, the classification is used operationally by the Swiss avalanche forecasting centre in the following way:

- class thresholds are used for colour coding and interpretation of the index (Fig. 4);

- index values are used for inter-annual comparison (Fig. 4, inset upper right corner).

The snowpack structure index provides a simple method to include snowpack information relevant to dry-snow slab avalanche release to gain a spatial overview of current snowpack structure and to illustrate the temporal development. It 
Table 6. Comparison of 11 simplified, typical profile types by manual snowpack structure classification $\mathrm{SNPK}_{\text {manual }}$, the calculated SNPK $_{\text {index }}$ and the classes derived from $\mathrm{SNPK}_{\text {index }}$ for profiles shown in Fig. 3.

\begin{tabular}{lccccccccccc}
\hline Snow structure & A1 & A2 & A3 & A4 & B1 & B2 & C1 & C2 & D1 & D2 & D3 \\
\hline SNPK $_{\text {manual }}$ & 5 & 4 & 2 & 5 & 2 & 3 & $1-2$ & $3-4$ & 2 & 3 & 5 \\
SNPK $_{\text {index }}$ & 1.15 & 1.65 & 2.12 & 0.99 & 2.18 & 1.58 & 2.16 & 1.34 & 2.09 & 1.59 & 1.45 \\
SNPK $_{\text {index }} \rightarrow$ classes & 4 & 3 & 2 & 4 & 2 & 3 & 2 & 3 & 2 & 3 & 3 \\
\hline
\end{tabular}

\section{Snowpack structure 2013-03-20 [10 days]}

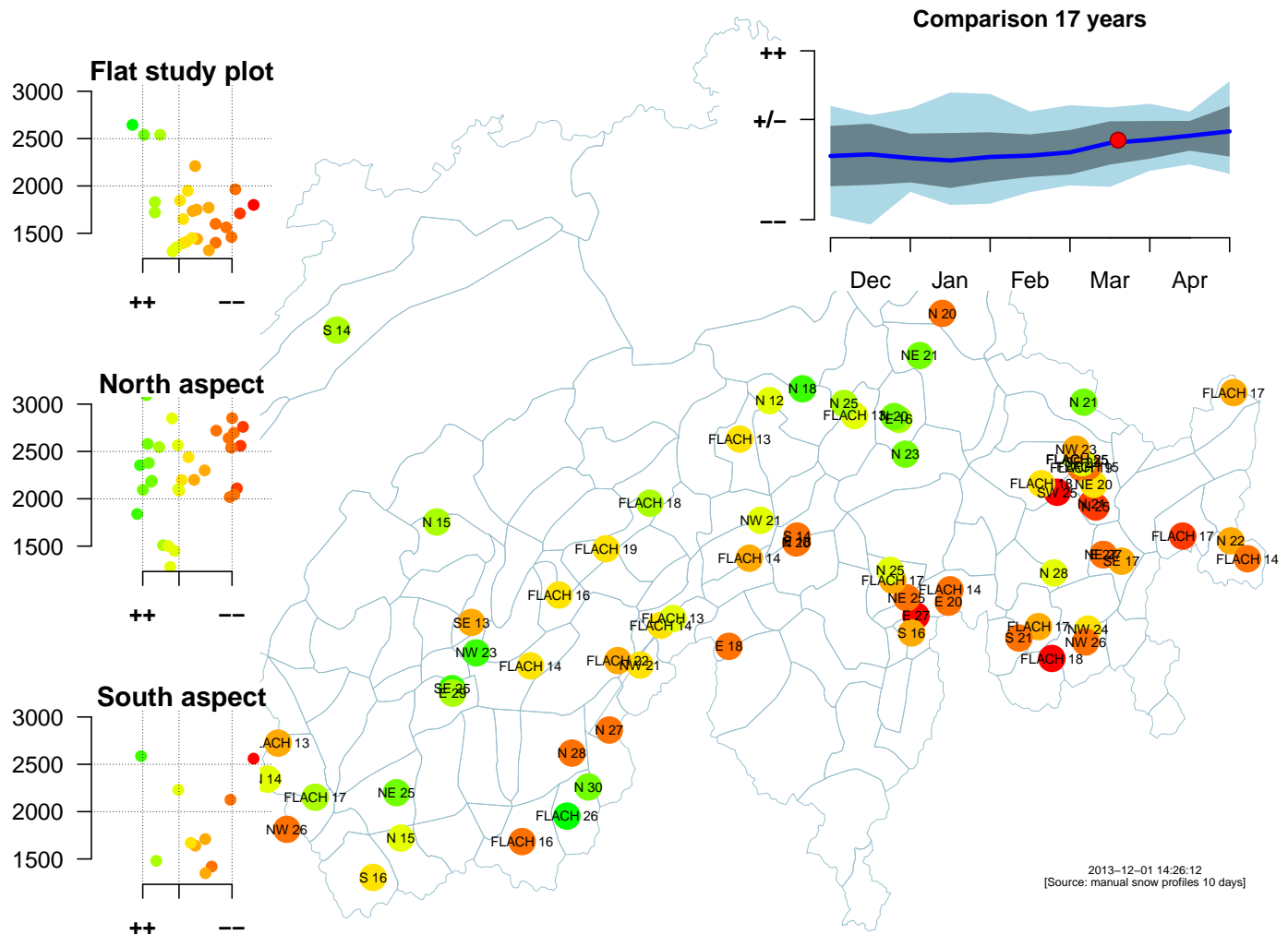

Fig. 4. Map of Switzerland showing the locations where manual profiles were observed (main graph, coloured points). Colour coding corresponds to the five classes calculated from $\mathrm{SNPK}_{\text {index }}$ (red: unfavourable $(--)$; yellow: medium $( \pm)$; green: favourable $(++)$ ). Each point represents one profile with the slope aspect and elevation given (e.g. N 15 is north aspect at $1500 \mathrm{~m}$ ). In the background the shapes of the 120 forecast regions are shown. The insets on the left side of the plot show the profiles according to aspect and elevation. The inset in top right corner gives a comparison of the actual conditions (red point) with the previous 17 years, where the mean is the blue line; the grey-shaded areas are \pm 1 standard deviations from the mean and the light-blue-shaded area the minima and maxima during this period.

may also be used for historical analysis of avalanche events or for snow-climatological investigations. Using the adjusted threshold sum approach for a simulated snowpack (Monti et al., 2012), it might be possible to apply a similar approach to modelled snow profiles such as the snowpack simulation SNOWPACK. This could increase the information density regarding snowpack structure information for avalanche forecasting services.
Acknowledgements. We greatly thank the (current and former) SLF avalanche forecasters Gian Darms, Lukas Dürr, Hans-Jürg Etter, Stephan Harvey, Thomas Stucki, Kurt Winkler, and Benjamin Zweifel. We would also like to take the opportunity to thank the SLF observers who provided us with the invaluable snow profile observations. We thank Kurt Winkler, Alec van Herwijnen, Jürg Schweizer and the two external reviewers Thomas Wiesinger and Fabiano Monti for their valuable comments, which greatly helped to improve the manuscript.

Edited by: R. Lasaponara

Reviewed by: T. Wiesinger and F. Monti 


\section{References}

Crawley, M.: The R book, John Wiley and Sons Ltd., 1st Edn., 2007. Fierz, C., Armstrong, R. L., Durand, Y., Etchevers, P., Greene, E., McClung, D. M., Nishimura, K., Satyawali, P. K., and Sokratov, S. A.: The International Classification for Seasonal Snow on the Ground, IHP-VII Technical Documents in Hydrology $\mathrm{N}^{\circ} 83$, IACS Contribution $\mathrm{N}^{\circ} 1$, UNESCO-IHP, Paris, 2009.

Föhn, P.: The rutschblock as a practical tool for slope stability evaluation, IAHS-AISH P., 162, 223-228, 1987.

Habermann, M., Schweizer, J., and Jamieson, B.: Influence of snowpack layering on human-triggered snow slab avalanche release, Cold Reg. Sci. Technol., 54, 176-182, 2008.

Haegeli, P. and McClung, D.: Expanding the snow climate classification with avalanche relevant information - initial description of avalanche winter regimes for south-western Canada, J. Glaciol., 53, 166-276, 2007.

Hothorn, T., Hornik, K., and Zeileis, A.: Unbiased recursive partitioning: a conditional inference framework, J. Comput. Graph. Stat, 15, 651-674, 2006.

Jamieson, B. and Johnston, C.: Refinements to the stability index for skier-triggered dry-slab avalanches, Ann. Glaciol., 26, 296-302, 1998.

McCammon, I. and Sharaf, D.: Integrating strength, energy and structure into stability decisions: so you dig a pit and then what?, Avalanche Rev., 23, 18-19, 2005.

Monti, F., Cagnati, A., Valt, M., and Schweizer, J.: A new method for visualizing snow stability profiles, Cold Reg. Sci. Technol., 78, 64-72, 2012.
Schweizer, J.: The rutschblock test - procedure and application in Switzerland, Avalanche Rev., 20, 14-15, 2002.

Schweizer, J. and Jamieson, B.: A threshold sum approach to stability evaluation of manual profiles, Cold Reg. Sci. Technol., 47, 50-59, 2007.

Schweizer, J. and Jamieson, J.: Snow cover properties for snow profile interpretation, Cold Reg. Sci. Technol., 37, 233-241, 2003.

Schweizer, J. and Lütschg, M.: Characteristics of human-triggered avalanches, Cold Reg. Sci. Technol., 33, 147-162, 2001.

Schweizer, J. and Wiesinger, T.: Snow profile interpretation for stability evaluation, Cold Reg. Sci. Technol., 33, 179-188, 2001.

Schweizer, J., McCammon, I., and Jamieson, B.: Snowpack observations and fracture concepts for skier-triggering of dry-snow slab avalanches, Cold Reg. Sci. Technol., 51, 112-121, 2008.

Sigrist, C. and Schweizer, J.: Critical energy release rates of weak snowpack layers determined in field experiments, Geophys. Res. Lett., 34, L03502, doi:10.1029/2006GL028576, 2007.

Simenhois, R. and Birkeland, K.: The extended column test: a field test for fracture initiation and propagation, in: Proceedings 2006 International Snow Science Workshop, Telluride, Colorado, 7985, 2006.

van Herwijnen, A. and Jamieson, B.: Snowpack properties associated with fracture initiation and propagation resulting in skiertriggered dry snow slab avalanches, Cold Reg. Sci. Technol., 50, 13-22, doi:10.1016/j.coldregions.2007.02.004, 2007.

Winkler, K. and Schweizer, J.: Comparison of snow stability tests: extended column test, rutschblock test and compression test, Cold Reg. Sci. Technol., 59, 217-226, 2009. 